\title{
José Carlos de Ataliba Nogueira Professor Catedrático de Direito Publico e Constitucional
}

Nasceu o dr. José Carlos de Ataliba Nogueira, em 29 de maio de 1901, na cidade de Campinas, deste Estado, filho de João de Ataliba Nogueira Junior e de d. Alexandrina Loureiro de Ataliba Nogueira.

Fez seus estudos primários no 2..$^{\circ}$ Grupo escolar de Campinas, no Licêu Salesiano Nossa Senhora Auxiliadora, da mesma cidade, e no Seminário Episcopal de Pouso Alegre (Minas Gerais), tendo feito todo o curso secundário no Ginásio Diocesano Santa Maria, de Campinas, recebendo o gráu de bacharel em ciências e letras.

Matriculou-se, nesta Faculdade, em 1921, colando grau de bacharel em ciências jurídicas e sociais, no dia 20 de dezembro de 1925. Foi orador oficial do Centro Acadêmico "XI de Agosto", havendo tomado parte ativa em todas as festividades e comemorações acadêmicas, notadamente no Congresso de estudantes e demais festejos do centenario da Independência nacional, em 1922, cabendo-lhe, ainda, saudar os cadetes mexicanos e numerosas personalidades estrangeiras, que visitaram a Academia. Colaborou em "O XI de Agosto" A' sua atuação como estudante refere-se o professor SPEncer Vampré, no final do $2 .^{\circ}$ volume das "Memórias para a História da Academia de São Paulo"

Durante o curso acadêmico, sucessivamente, foi redator do "Jornal do Comércio", edição de São Paulo, escriturário da Estrada de Ferro Sorocabana e, por concurso, da Secretaria da Fazenda e do Tesouro do Estado, professor dos curso diurno e noturno do Licêu do Sagrado Coração de Jesús. Como presidente da Congregação Mariana de Santa Ifigênia, foi um dos instituidores da comunhão pascal dos 
acadêmicos e das comemorações da data da fundação da cidade (25 de janeiro), junto ao monumento do Pátio do Colégio.

Foi nomeado lente interino da cadeira de Instrução Moral e Civica do Cinásio do Estado, na capital, por decreto de 18 de fevereiro de.1926, onde regeu, ainda em carater interino, a cadeira de latim. Foi nomeado promotor público da comarca de Itapetininga, por decreto de 28 de dezembro de 1926. Nessa cidade, tambem lecionou português, no curso ranexo da Faculdade de Farmácia e Odontologia. Foi promovido a $5 .^{\circ}$ promotor publico da capital, a 16 de dezembro de 1927. Neste cargo, frequentou assiduamente a tribuna do juri e exerceu várias comissões, tendo sido, mais de uma vez, designado Procurador Geral do. Estado "ad hoc". Foi tambem representante do Ministério Público no Consêlho Penitenciário.

Em 1932 e 1933, fez o curso de doutoramento, desta Faculdade.

De novembro de 1932 a junho de 1933, foi secretário do govêrno militar do Estado de São Paulo e seeretário da -interventoria.

Quando frequentava o $2 .^{\circ}$ ano jurídico, matriculou-se tambem na Faculdade de Filosofia Ciências e Letras de ${ }^{4} \mathbf{S}$. Bento, nesta capital, da quàl é professor catedrático da cadeira de Sociologia, desde 1936. Foi professor catedrático de direito penal (1. ${ }^{\mathrm{a}}$ cadeira) da extinta Faculdade 'Paulista de Direito.

Em 1937 e 1938, respetivamente, fez concursos para professor catedrático de direito penal $\left(1 .^{\mathrm{a}}\right.$ e $2 .^{\mathrm{a}}$ cadeiras $)$ desta Academia, em virtude do primeiro dos quais foi nomeado livre ‘docente desta disciplina, colando grau de doutor em direito e tomando posse da livre docência, a 26 de outubro de 1937.

No concurso de trabalhos jurídicos, realizado pelo Instituto dos Advogados de São Paulo, em 1937, obteve o primeiro dogar o seu livro "Medidas de segurança". 
Na elaboração do seu Projeto de código criminal, o professor Alcântara Machado aproveitou mais de uma das conclusões da obra científica do prof. Ataliba Nogueira, no tocante ao capitulo das medidas de segurança.

Em junho de 1939, o professor J. C. Ataliba Nogueira chefiou uma delegação universitária, composta de oito alunos desta Faculdade, que, a convite da Faculdade de Direito da Universidade de Chile, visitou aquela nação sul-americana. Proferiu conferências na Universidade de Chile, na Universidade Católica, tambeń de Santiago, no Instituto de Ciências Penales da mesma cidade, havendo visitado a Faculdade de Direito de Valparaiso, assim como, na Argentina, as de Buenos Aires e La Plata, e, no Uruguai, a de Montevidéu.

O relevo que deu à representação cultural da Faculdade, no estrangeiro, é provado pela distinção por ele recebida do governo do Chile, que lhe conferiu a condecoração "Al Mérito", no gráu de comendador, sendo-lhe entregue a comenda, solenemente, na data americana de 12 de outubro de 1940, no consulado desta capital pelo consul daquela nação amiga, dr. Miguel Inácio Bravo, tambem professor em Santiago.

E' sócio efetivo e orador oficial do Instituto Histórico e Geográfico de São Paulo; sócio correspondente do Instituto Histórico e Geográfico da Paraiba; sócio tutular da Sociedade de Medicina Legal e Criminologia de São Paulo; sócio efetivo do Centro d. Vital, de São Paulo; sócio efetivo do Instituto de Estudos Genealógicos; sócio honorário da Associação dos Jornalistas Católicos; membro da Ordem dos Advogados, secção de São Paulo.

Sua atividade, na imprensa, principiou em "A Pena", órgão do Ginásio Diocesano Santa Maria, de Campinas; fundou e foi diretor de "A Gazeta de Jaguarí" (1919) ; secretário de redação de "O Mensageiro da Paz" (São Paulo); redator do "Jornal do Comércio", de São Paulo; colaborador de "A Gazeta"; colaborador de "O XI de Agosto"; fundador 
e diretor do "Diário Paulista", da capital; colaborador de "A Tribuna", de Itapetininga; do "Diário de São Paulo", e de "O Jornal", do Rio.

Por decreto de 20 de março de 1939, foi designado para reger a cadeira vaga de direito público e constitucional, para o preenchimento da qual se submeteu a concurso e, obtendo a classificação em primeiro logar, foi nomeado professor catedrático dessa disciplina, por decreto de 8 de outubro de 1940. Tomou posse, em sessão colena da Congregação, no dia 12 do mesmo mês e ano, sessãa a que presidiu o professor Sebastião Soares de Faria, diretor da Faculdade de Direito.

Saudando o novo catedrático em nome da congregação, o professor J. Canuto Mendes de Almeida proferiu o seguinte discurso:

"Quer a Congregação da Faculdade de Direito, jubilosa pela investidura de V Ex., sr. dr. Josè Carlos de Ataliba Nogueira, no exercício efetivo da cátedra de Direito Público e Constitucional, que as palavras de seu delegado-orador, nesta solenidade, exprimam, em relêvo, a plenitude desse júbilo, no tom de alegria que todos os professores desejamos ver refletida, como própria, nas palavras desta saudação.

A designação, na minha pessoa, daquele que as deveria proferir representa, por certo, honrosa e desvanecedora consideração, dada ao menos habilitado para isso, pelos sabidos sentimentos de especial amizade que me unem ao homenageado. $\mathrm{O}$ afeto cega os homens: onde, pois, devêra falar, tão só, a voz equilibrada do límpido e desapaixonado acolhimento, elevar-se-ia, para sobranceá-la, o doce, mas desordenado, rugido do coração.

Essas duas razões, entretanto, não me constrangem, porque cedem ao especial significado da minha escolha: a Congregação da Faculdade saúda o novo catedrático, não só pela palavra de um de seus professores, mas também e propositadamente pela de um grande amigo, para que, aqui, neste discuros, sua satisfação apareça, não fórmula vazia e convencional de nosso regulamento, mas plena da sinceridade em que ora se transfunde. 
Nós, os professores, participamos da alegria de V Ex. e de todos os seus, porque a felicidade alheia dá alegria aos corações bem formados: porque, no caso, esta felicidade deriva da honra que ser professor nesta Faculdade representa; e principalmente porque confiamos em que o novo catedrático ha de reafirmar, na nova faze de sua vida, as notórias qualidades intelectuais e morais, que soube, até hoje, revelar, como jornalista, promotor público, professor de Sociologia, de Direito Penal, e de Direito Público e Constitucional (no exercício provisório deśa mesma cadeira em que se efetiva).

A afabilidade de trato des homens, aliada ao brilho invulgar dessas qualidades intelectuais e morais, cercam V. Ex. de uma atmosfera de carinhoso confôrto, quando e onde quer que tenham sido reveladas. Isso explica, suficientemente, a dedicação entusiástica de seus amigos e a simpatia de todos os que de perto conhecem a V. Ex.

Ainda ha pouco, numa viagem ao Chile, grangeou $\mathrm{V}$ Ex., para sua pessoa e para esta Faculdade, graças àqueles predicados, a admiração dos universitários e de autoridades daquele paiz, com o lisongeiro galardão da Ordem "Al Mérito", que, hoje mesmo, digno complemento desta solenidade, vai ser entregue a V Ex. pelo sr. consul do Chile.

São tais qualidades intelectuais e morais, afinal, penhor seguro de crescente valor das lições que, aqui hão de ser por V. Ex. ministradas às gerações do presente e do futuro, na ininterrupta e tradicional tarefa da Academia, de prègar Justiça aos brasileiros e de neles infundir amor à liberdade e ao Direito"

O professor J. C. Ataliba nogueira respondeu nestes termos:

"Abre-se para mim nova fase da vida, tal a estimação que atribuo à minha entrada definitiva nesta douta congregação de professores. 
Todavia, não ha mudança de roteiro, nem substituiçâf de ideiais, porquanto continuarei ao serviço da mesma caus a que me tenho dedicado, com todas as forças, sem desfale cimento - a justiça e o direito.

Filho desta mesma Faculdade, frequentei-lhe os bancoss. acadêmicos, com a decisão de me consagrar a uma das carreiras correspondentes à minha vocação para $\theta$ direito. Recem formado, ingressei na promotoria pública. Foram 14 anos de trabalhos fartamente recompensados por uma convivência verdadeiramente felì e proveitosa, com juizes de direito, colegas do Ministério Público, advogados, escrivães e demais funcionários forenses, dos quais recebí sempre deferência toda especial, provas verdadeiras de estima, o que me é grato neste momento recordar, afim de a todos dirigir o meu agradecimento muito sincero.

Foi precisamente em meio ao afanoso serviço forense e devido à necessidade de aprofundar dificeis questões jurídicas, frequentes no pretório, numa emulação por todos os títulos digna, com colegas e defensores, esperando a decisão de juízes cultos, que desejei aquilo que de princípio me parecia mero anelo evanescente pela pequenez de quem se reconhecia tão distante dos professores desta casa, muitos deles seus mestres no bacharelado e no doutoramento.

Ha quase três anos aqui me encontro entre vós. Entrei para o vosso meio como o novo levita penetrava outróra o "sancta sanctorum", temeroso por delustrar uma congregação de doutos juristas. $O$ benévolo acolhimento, o trato diário, a convivência de tantos mêses, o contacto com a cultura e a inteligência me não cativaram apenas, pois ainda maior se me afigurou a honra que se me dá neste momento, a de pertencer definitivamente à congregação dos professores da Faculdade de Direito de São Paulo. De tudo quanto disse, porque é tudo quanto aquí vi e aquí experimentei, prova sobeja é a formosa saudação em vosso nome e mim dirigida pelo meu querido amigo o professor Canuto Mendes de ALMEIDA. 
A mim só me é dado, senhores professores, além do meu profundo apradecimento, dizer-vos que tudo farei para corresponder às vossas simpatias, aos vossos votos e às minhas esperanças. Tudo farei para o maior engrandecimento desta Facudade, de cujas tradições nobres e elevadas procurarei ser devotado servidor. Acostumado a esta estima fervorosa, desde minha casa, onde meu avô, tambem filho desta Academia, me ensinou a reverenciá-la; estudante aquí e dos de vida acadêmica mais ativa; egresso de suas salas de aula, mas delas nunca distante pelo coração e pela prática do ensinamento haurido em suas cátedras, passo hoje a ocupar a regência da de Direito Público e Constitucional, em parte com desvanecimento, em parte com fundada apreensão, já por ter de tomar assento entre mestres ilustres, já por saber que foi ela engradecida por alguns dos maiores cultores deste ramo do direito, dentre todos se salientando o saudoso Herculano de Freitas e o meu querido amigo professor Sampáio DóRia.

Tudo farei, senhores professores, para merecer sempre a vossa estima afetuosa e a vossa honrosa consideração. Continuareis a ser os meus mestres, convosco aprendendo, não apenas o cultivo do direito, mas ainda o escrupuloso cumprimento do dever. Contareis comigo na união de esforços em pról do ensino universitário, na unidade admiravel, que afasta os dissídios e os malentendidos para a mútua compreensão; finalmente, numa amizade verdadeira e sincera, que a todos nos vincule, em tôrno da centenária Academia.

A Deus peço que me abençôe as intenções e que possa corresponder à grandeza da obra de que sou modesto operário"

OBRAS PUBLICADAS

Trabalhos jurídicos:

1. “A REFORMA DA CONSTITUIÇÃO FEDERAL”, São Paulo, 1926 ; 
2. "A INSTRUÇão MORAL E CfVICA" São Paulo, 1926;

3. "VADIAGEM", São Paulo, 1928;

4. “COMBATE ÀS PUBLICAÇõES IMORAIS”, São Paulo, 1929;

5. “AS LOTERIAS ESTADUAIS E O FISCO”, São Paulo, 1930;

6. "MEDIDAS DE SEGURANÇA", São Paulo, 1937;

7 "PENA SEM PRISÃO", São Paulo, 1938;

8. “O ESTADO E UM MEIO E NÃO UM FIM”, São Paulo, 1940.

Outros trabalhos publicados:

1. "SANTO ANTõnIO NA TRADIÇÃO BRASILEIRA" São Paulo, 1933;

2. “UM INVENTOR BRASILEIRO”, São Paulo, 1934. 